\title{
Interactive comment on "1.5 years of TROPOMI CO measurements: Comparisons to MOPITT and ATom” by Sara Martínez-Alonso et al.
}

\section{Anonymous Referee \#3}

Received and published: 2 May 2020

The authors have conducted a validation of TROPOMI CO retrievals using data from MOPITT and aircraft profiles of CO from ATom. The TROPOMI data are fairly new and provide tremendous observational coverage at high spatial resolution. However, MOPITT offers a uniquely long record of space-based measurements of $\mathrm{CO}$, therefore there is significant value in the validation analysis presented here. My main concern is that when comparing two remote sensing data sets it is critical to account for the influence of the a priori profiles on the retrievals and for the different vertical sensitivities of the measurements, which was not done in this study. The manuscript is well written and appropriate for AMT. I would recommend publication of the manuscript after the authors have addressed my comments below. 
1. Lines 111-114: The discussion here is somewhat confusing. The authors state that the NIR retrievals are significantly constrained by the a priori, whereas the TIR are less strongly weighted by the a priori profile. However, on lines 159-160 they explain that they do not transform the MOPITT and TROPOMI profiles when comparing them. It would seem that the different contributions of the a priori to the two sets of retrievals would necessitate accounting for the influence of the a priori profiles to meaningfully compare the two data sets. What is the justification for neglecting this?

2. Lines 162-163: What is the impact of the differences in the overpass times of TROPOMI and MOPITT when selecting "collocated" pairs of data? Quantifying this for the ROls selected in the study would be helpful for interpreting the results of the intercomparison.

3. Lines 307-308: What is the implication of the tendency of the reference profiles to have too much $\mathrm{CO}$ near the surface for the intercomparison with MOPITT, considering that no attempt is made to mitigate potential biases arising from the a priori?

4. Lines 354-357: It is certainly possible that the differences in overpass times could contribute to these biases over Africa, but this can be confirmed with a model, for example. Furthermore, what about the impact of the different vertical sensitivities of the measurements here? It seems critical to me to account for the influence of the averaging kernels before speculating that these differences could be due to temporal variations in the African fires.

\section{Technical Comments}

1) Line 46: This is not the first use of the acronym MOPITT.

2) Line 110: Please insert "the" before "total column AK".

3) Line 119: Please make it clear that "( 480 ; note $1 \mathrm{~km}$ resolution)" here is referring to the number of MODIS observation, and that these observations have a resolution of $1 \mathrm{~km}$.

Printer-friendly version

Discussion paper
Interactive comment 
Interactive comment on Atmos. Meas. Tech. Discuss., doi:10.5194/amt-2020-63, 2020.

AMTD

Interactive comment 